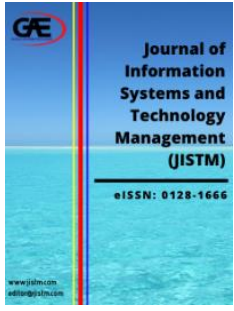

\author{
JOURNAL OF INFORMATION \\ SYSTEM AND TECHNOLOGY \\ MANAGEMENT (JISTM)

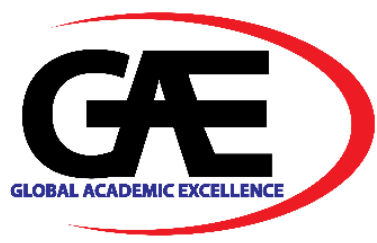

\title{
CONSTRUCTION DISPUTE AND CONTRACT DOCUMENT DEFECTIVENESS: TESTING MODERATING EFFECT OF BIM
}

\author{
Olalekan Olaolu Titus*1, Hamizah Liyana Tajul Ariffin ${ }^{2}$, Kherun Nita Ali ${ }^{3}$
}

1 Department of Quantity Surveying, Faculty of Built Environment \& Surveying, Universiti Teknologi Malaysia, 81310 UTM Johor Bahru, Johor, Malaysia

Email: olaolu@graduate.utm.my

2 Department of Quantity Surveying, Faculty of Built Environment \& Surveying, Universiti Teknologi Malaysia, 81310 UTM Johor Bahru, Johor, Malaysia

Email: hamizah@utm.my

3 Department of Quantity Surveying, Faculty of Built Environment \& Surveying, Universiti Teknologi Malaysia, 81310 UTM Johor Bahru, Johor, Malaysia

Email: b-kherun@utm.my

* Corresponding Author

\section{Article Info:}

Article history:

Received date: 01.10 .2021

Revised date: 01.11.2021

Accepted date: 20.11.2021

Published date: 01.12.2021

\section{To cite this document:}

Titus, O. O., Ariffin, H. L. T., \& Ali, K. N. (2021). Construction Dispute And Contract Document Defectiveness: Testing Moderating Effect Of BIM. Journal of Information System and Technology Management, 6 (24), 100-108.

DOI: $10.35631 / J I S T M .624010$

This work is licensed under $\underline{\mathrm{CC} B Y} 4.0$

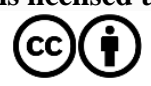

\section{Abstract:}

Construction dispute is the result of contract incompleteness caused by bounded rationality and uncertainty. These disputes are prevalent and have a detrimental effect on project success in terms of increased cost, low quality of work, loss of profit, time extension, and damaged business and professional relationships. Using Structural Equation Modelling (SEM), this study examines the relationship between contract defectiveness (one of the bounded rationality classes) and dispute occurrence and the moderating effect of BIM on the causal relationship. The result shows that contract document defectiveness has a significant effect on dispute occurrence. Likewise, the multigroup moderation test revealed a significant, positive, and more substantial impact on the BIM user group. Therefore, it can be posited based on this study's findings that BIM has a significant effect on reducing contract document defectiveness, which is one of the potential benefits of its adoption on construction projects.

Keywords:

Dispute 1, Contract Incompleteness 2, BIM 3 


\section{Introduction}

Construction disputes resulting from contract defectiveness are not bizarre. These disputes are prevalent, endemic, and bring adverse effects on project performance in terms of increased cost, low quality of work, loss of profit, time extension, damaged business and professional relationships (Sai On Cheung \& Pang, 2013). Modern contracts with the advent of technological development are complex, given the rising to complex activities in a fragmented environment with a high uncertainty level (Mashwama, Aigbavboa, \& Thwala, 2016). The complexity in the construction project, accuracy of contract document in a futuristic environment is always challenging and, most time leads to disputes (Ejohwomu, Oshodi, \& Onifade, 2016). Hughes, Murdoch, and Champion (2015) define contract documents as the mechanism by which designers' intentions are transmitted to the client, the statutory authorities, the quantity surveyor, the contractor, and subcontractors. While contract document is expected to convey the intention of designer to different parties, complex contracts are in most cases invariably incomplete.

Yates (1998), based on Transaction Cost Economic Theory (TCE) (Williamson, 1983), posited that complex contracts are invariably incomplete, particularly those executed over a long period. A contract is incomplete when, at the inception, it does not explicitly define all the parties' requirements and obligations in any possible future state of the world. When events arise during the contract's execution, the parties' complete requirements and obligations are understood, and necessary modification and adaptation are needed. Predictably, such behaviour results in conflict and dispute. Cheung (2014) likewise used TCE theory to conceptualize contractual and speculative disputes and suggested that contracts' incompleteness is a fundamental element in both disputes. The study concluded that contract incompleteness caused by bounded rationality and uncertainty are the underlying root cause of disputes.

Bounded rationality is the human limitation to foresee all future occurrences at the outset of the project (Williamson, 2014), while uncertainty is the difference between the amount of information required to do the task and the amount of information already processed by the organization (Galbraith, 1973). When there is ambiguity, the contract is open to differing interpretations of performance requirements among the contracting parties (Howell \& Mitropoulus, 2001). While contract incompleteness cultivates unseen perils, opportunism may manifest through violation of contractual requirements.

Contract incompleteness sets the stage for opportunism. Cheung (2014) defines opportunism at work as a situation when an individual attempts to maximize his interest in any situation where he could gain one way or another. Opportunistic behaviour may yield to post-contractual manipulation of contract terms to affect the other party's unexpected transfer of wealth. The concept of bounded rationality is broken down into four major classes: ambiguity, deficiency, inconsistency, and defectiveness. While contract incompleteness cultivates the problems, opportunism manifests through violation of commitment, forced renegotiation, evasion of obligations, and refusal to adapt.

Several standards and methods have evolved with the presentation and documentation of construction information over the years. The traditional/ manual setting provides 2D drawings and written instructions to build what the designer has visualized in his head. This seems to be an imperfect way of information sharing, planning, and building complex project. Similarly, $2 \mathrm{D}$ drawing required translation of each instruction in one's head until the resulting instruction 
is visualized and built correctly. The translation of each instruction between team members may lead to error. Additionally, the traditional setting cannot visualize and verify the coordination process before the actual construction. Therefore, most projects have many requests for information (RFI) about the documentation of the project, and there is the expectation of dispute (Kymmell, 2008).

Building Information Modelling (BIM) offers a paradigm shift from the traditional settings rooted in 2D drawings. It is a process based on the software application that changes designing and building(Saka, Chan, \& Siu, 2019). Moreover, it offers an efficient, faster design process, with fewer errors and safer construction. According to Charehzehi, Chai, Yusof, Chong, \& Loo (2017). BIM approach can control conflict causes before the occurrence of dispute. Furthermore, BIM virtual design \& construction (VDC) gives access to all information regarding the project, with this area of conflict can be identified easily. (Sacks et al., 2018).

Therefore, this study intends to examine the relationship between contract document defectiveness (CDD) as one of the classes of bounded rationality and dispute occurrence (DOC) and examine the moderating effect of BIM on the causal relationship using multigroup moderation in Nigeria construction industry. The following hypothesis using Structural Equation Modelling (SEM) will be tested in this study.

$\mathrm{H}_{1}$ : CDD has a significant effect on DOC

$\mathrm{H}_{2}$ : BIMuse moderate relationship between CDD \& DOC

\section{Methodology}

\section{Measuring Instrument}

Two constructs related to construction disputes and contract incompleteness are incorporated in the proposed model. The two constructs were measured using a total of 13 questions. The first parts cover the demography features of the sample as seen in Table 1, while the second part covers the responses to the questions which are measured using a five-point Likert scale ranging from " 1 = strongly disagree" to " $5=$ strongly agree" (Brown, 2010) with 6 and 7 items measuring each construct respectively.

Table 1: Demography Characteristics of the Sample

\begin{tabular}{c|c|c}
\hline Demography & Frequency & Percentage \\
\hline BIM Use & & \\
\hline BIM User & 140 & 45.3 \\
\hline Non-BIM User & 169 & 54.7 \\
\hline Years of Experience & & \\
\hline 1-10Years & 73 & 23.6 \\
\hline 11-20Years & 112 & 36.2 \\
\hline 21-30 Years & 65 & 21.0 \\
\hline 31-35Years & 41 & 13.3 \\
\hline Above 35 Years & 18 & 2.5 \\
\hline Certificate & & \\
\hline OND & 73 & 23.6 \\
\hline HND & 112 & 36.2 \\
\hline BSc & 65 & 21.0 \\
\hline MSc & 41 & 13.3 \\
\hline
\end{tabular}


Volume 6 Issue 24 (December 2021) PP. 100-108 DOI: 10.35631/JISTM.624010

\begin{tabular}{c|c|c}
\hline Ph. D & 18 & 5.8 \\
\hline Reg. Body & & \\
\hline QSRBN & 56 & 18.1 \\
\hline ARCON & 56 & 18.1 \\
\hline COBON & 48 & 15.5 \\
\hline COREN & 53 & 17.2 \\
\hline NIESV & 44 & 14.2 \\
\hline PMI & 52 & 16.8 \\
\hline
\end{tabular}

\section{Data Analysis}

Structural equation modelling (SEM) was employed for the analysis of the study. SEM is a useful statistical tool that allows the evaluation and simultaneous estimation of multiple equations encompassing factor analysis, multiple regression analysis, and path model analysis (Joe F.Hair, Matthews, Matthews, \& Sarstedt, 2017). The software allows testing the whole relationship among latent constructs that are indicated by multiple measures in a research model as well as differentiating between a direct and indirect.

\section{Exploratory Factor Analysis (EFA)}

The EFA using Promax rotation shows that all variables have good loadings, observe fairly normal distributions for the latent factors and all variables in terms of skewness and kurtosis as there no values above $+/-2.2$ as the normality threshold (George \& Mallery, 2019). As shown in Table 2, the KMO and the chi-square result are significant indicating the suitability to conduct the EFA. Reliability and Discriminant validity of the variables appears good as the loading has a clean pattern structure obvious by the high loading factors above 0.7 and no crossloading of the items (Reid, Stephanie, Lewis, \& Armstrong, 2007).

Table 2: Pattern Matrix

\section{Pattern Matrix ${ }^{a}$}

\begin{tabular}{l|c|c}
\hline \multirow{2}{*}{$\begin{array}{l}\text { Cronbach's } \\
\text { alpha }\end{array}$} & \multicolumn{2}{|c}{ Component } \\
\cline { 2 - 3 } CDD1 & 0.910 & 0.903 \\
\hline CDD2 & & .864 \\
\hline CDD3 & & .865 \\
\hline CDD4 & & .870 \\
\hline CDD5 & & .727 \\
\hline CDD6 & & .825 \\
\hline DOC1 & .819 & \\
\hline DOC2 & .829 & \\
\hline DOC3 & .863 & \\
\hline DOC4 & .832 & \\
\hline DOC5 & .762 & \\
\hline DOC6 & .749 & \\
\hline DOC7 & .711 & \\
\hline
\end{tabular}


Extraction Method: Principal Component

Analysis.

Rotation Method: Promax with Kaiser

Normalization.

a. Rotation converged in 3 iterations.

\section{Structural Equation Modelling (SEM) Analysis}

\section{Model Fit}

The loading for the 2 constructs has a significant loading $\geq 0.60$. Modification indices were accessed to determine if there was a prospect to improve the model. Consequently, items e1, e3, e9 \& e14 were deleted and e11 \& 12 were covaried to obtain goodness of fit for our measurement model as shown in Figure 1

\section{Validity and Reliability}

Table 3 shows that the average variance extracted (AVE) ranges from 0.554 to 0.635 indicating that all values are more than the recommended 0.50 levels and no convergent validity issue (Niemand \& Mai, 2018). Testing for discriminant validity, the square root of the AVE is compared to all inter-factor correlations. The result shows that mean shared variance (MSV) is significantly lower than the AVE and established discriminant validity for the study. Likewise, the composite reliability (CR) was computed and it shows that the CF is above the 0.7 thresholds indicating we have reliability for all constructs (Joe F.Hair et al., 2017)

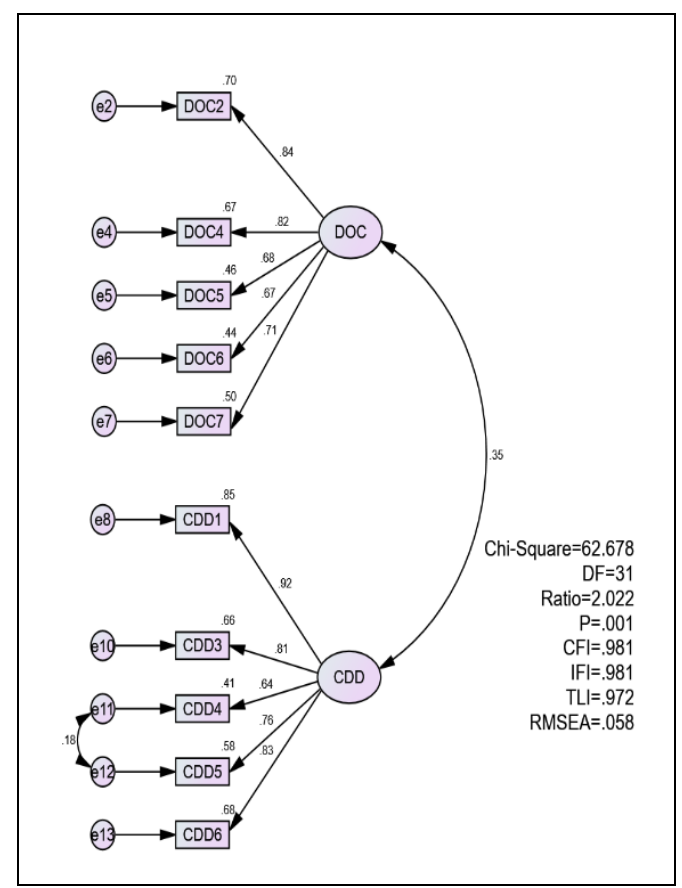

Figure 1: Measurement Model 
Table 3: Reliability and Validity

\begin{tabular}{l|c|c|c|r|r|r} 
& CR & AVE & MSV & MaxR(H) & \multicolumn{1}{c}{ DOC } & CDD \\
\hline DOC & 0.860 & 0.554 & 0.122 & 0.875 & 0.744 & \\
\hline CDD & 0.896 & 0.635 & 0.122 & 0.921 & $0.350 * * *$ & 0.79
\end{tabular}

\section{Invariance Test}

Since the study will be considering moderating the structural model with categorical variables, we conducted a configural invariance test. The model fit with group loaded separately was good $(\chi 2 / \mathrm{DF}=1.422 ; \mathrm{CFI}=0.979)$ signifying that the model is configurally invariant. likewise, after constraining the model to be equal, we discovered the chi-square difference test to be significant ( $\mathrm{p}=0.013$ ) as shown in Table 4, consequently, our measurement model satisfies the metric variance across the group.

\section{Main Result}

Figure 2 shows the results of the structural model with standardized parameters. The model displays a good fit (Joe F.Hair et al., 2017). The probability of getting a critical ratio as large as 5.615 in absolute value is less than 0.001. In other words, the regression weight for CDD in the prediction of DOC is significantly different from zero at the 0.001 level (two-tailed). Hypothesis $\mathbf{H}_{1}$ is supported and confirms the assertion of contract incompleteness as the cause of construction dispute as posited by Yates (1998) and Cheung \& Yiu (2014).

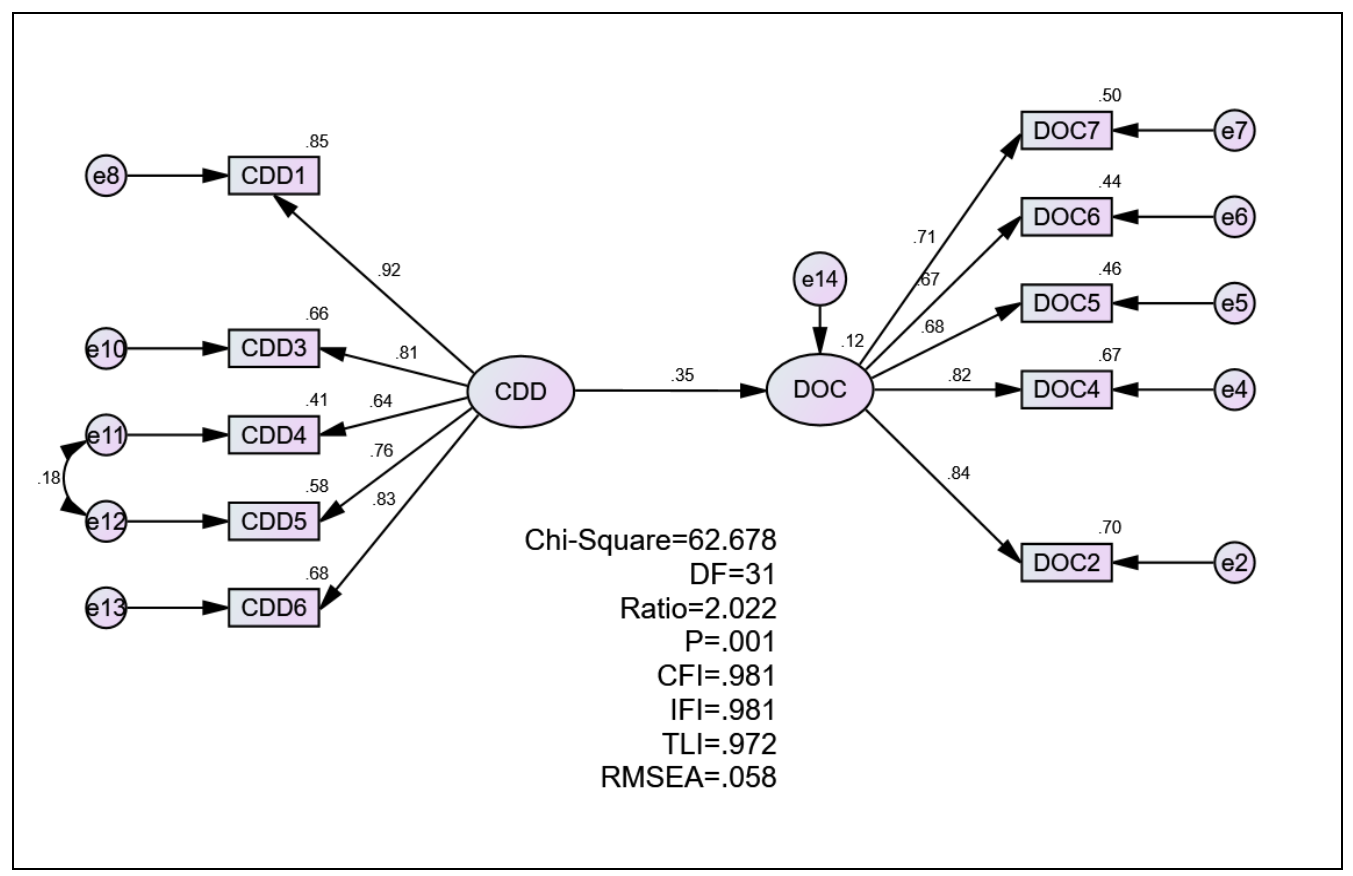

Figure 2: Structural Model

Multigroup moderation test was carried out for the model. The model was divided into two groups based on the moderator variable, as shown in figure 3. To test the moderation effect, the critical ratio for the constrained and unconstrained model was generated. From these critical ratios, the chi-square value between the constrained and unconstrained models is more than 3.84, as shown in Table 4. The result shows that moderator variable BIMuse significantly and 
positively moderates CDD's causal effect on DOC. Likewise, its effect is more substantial in the BIMuser group; therefore, hypothesis $\mathbf{H}_{2}$ is supported.

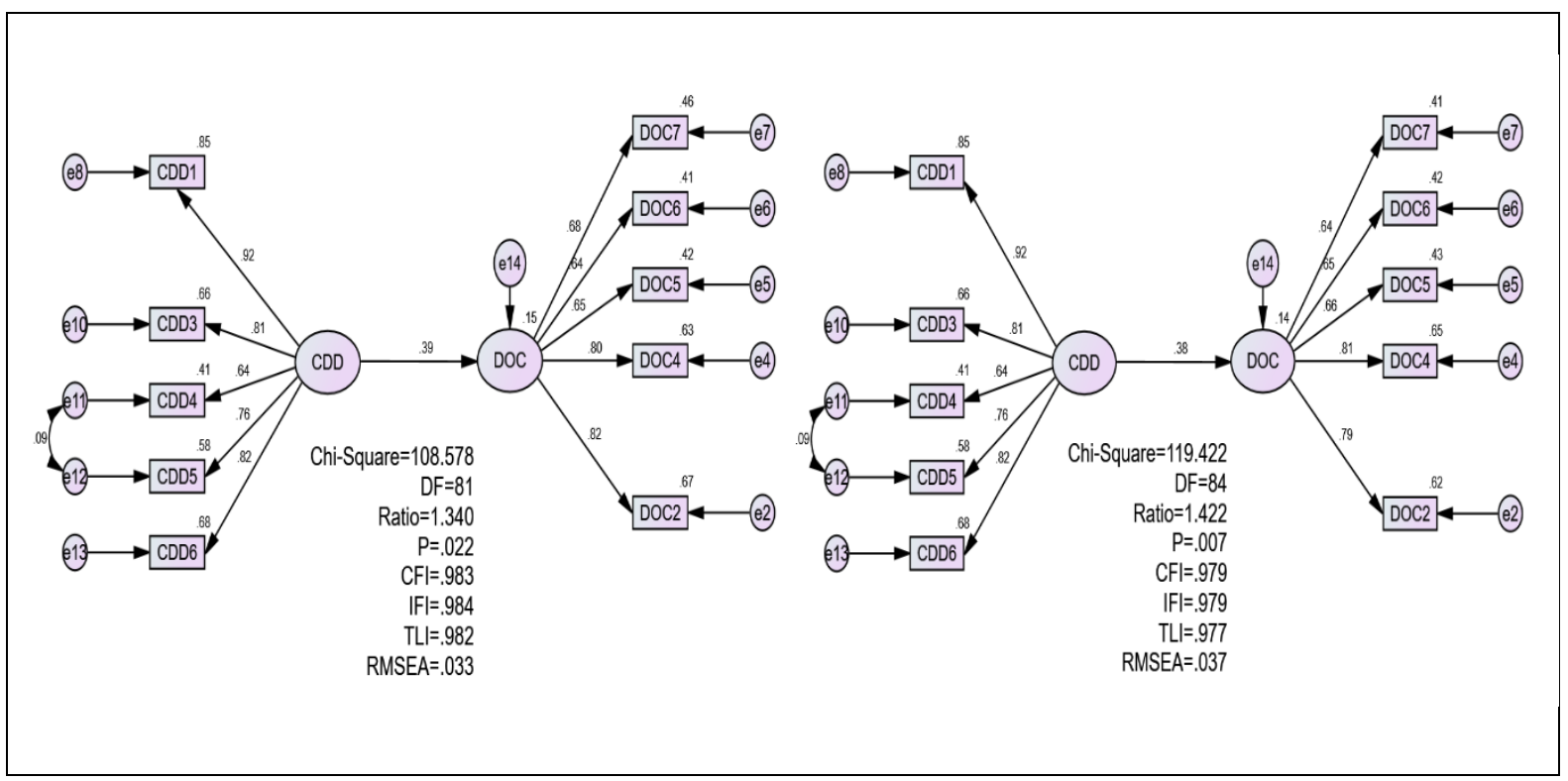

Figure 3: Constrained \& Unconstrained Model

Table 4: Moderation Test Table

\begin{tabular}{|l|c|r|r|}
\hline & Chi-square & df & p-val \\
\hline Model & & & \\
\hline Unconstrained & 108.578 & 81 & \\
\hline Fully constrained & 119.422 & 84 & \\
\hline Number of groups & & 2 & \\
\hline \multicolumn{1}{|c|}{ Difference } & $\mathbf{1 0 . 8 4 4}$ & $\mathbf{3}$ & $\mathbf{0 . 0 1 3}$
\end{tabular}

\section{Conclusion}

The study contributes to the few existing literature exploring the effect of contract incompleteness on dispute occurrence. In this study, construction dispute is discussed to occur due to contract incompleteness caused by bounded rationality and uncertainty. Likewise, the study attempts to test the causal relationship between contract documents defectiveness (CDD), one of the classes of bonded rationality and dispute occurrence (DOC). The result shows that CDD had a significant effect and adverse effect on DOC. This indicates that when a contract document is defective, the likelihood of dispute occurrence is high, which is similar to the assertion of Yates $(1998,2002)$ and Cheung \& Yiu (2014).

The moderating effect of BIM effects on the causal relationship was significant, positive, and decisive for the BIMuser. Therefore, it can be posited based on the findings of this study that BIM has a significant effect on reducing defectiveness of contract documents which is one of the potential benefits of its adoption in construction projects, as explained by Olawumi \& Chan (2019) and Saka et al., (2019). BIM captures, explore, coordinates, and maintains consistent data through the planning, design, construction, and operational phase (Kymmell, 2008; Wei \& Mydin, 2017). It is evident from this finding that the implementation of BIM played a vital role and exerted a profound impact on construction projects. It is recommended that BIM Copyright $\odot$ GLOBAL ACADEMIC EXCELLENCE (M) SDN BHD - All rights reserved 
Volume 6 Issue 24 (December 2021) PP. 100-108

DOI: 10.35631/JISTM.624010

adoption on projects should be promoted and mandated for complex projects to reduce dispute occurrence drastically on such projects.

\section{References}

Brown, S. (2010). Likert scale examples for surveys. ANR Program evaluation, Iowa State University, USA.

Cheung, S.O., \& Yiu, T. W. (2014). Online construction dispute negotiation. In Construction Dispute Research: Conceptualisation, Avoidance and Resolution, Springer International Publishing Switzerland, 213-230

Cheung, S.O. (2014). Conceptualising construction dispute. In Construction Dispute Research: Conceptualisation, Avoidance and Resolution Springer International Publishing Switzerland, 19-35

Cheung, S. O., \& Pang, K. H. Y. (2013). Anatomy of construction disputes. Journal of Construction Engineering and Management, 139(1), 15-23.

Ejohwomu, A., Oshodi, O., \& Onifade, M. (2016). Causes of conflicts in construction projects in nigeria: consultant's and contractor's perspective. Nigerian Journal of Technology. Vol 35(2)

Galbraith, J. R. (1973). Designing complex organizations. (3rd print.). Reading Mass AddisonWesley Pub. Co.

George, D., \& Mallery, P. (2019). IBM SPSS statistics 25 step by step : a simple guide and reference (Fifteenth). New York NY: Routledge.

Howell, G., \& Mitropoulus, P. (2001). A Model for Understanding. Preventing and Resolving Construction Dispute. 83340, Page no1-37.

Hughes, W., Murdoch, J. R., \& Champion, R. (2015). Construction contracts : law and management (5. ed.). Abingdon: Routledge.

Joe F.Hair, J., Matthews, L. M., Matthews, R. L., \& Sarstedt, M. (2017). PLS-SEM or CBSEM : updated guidelines on which method to use. International Journal of Multivariate Data Analysis, 1(2).

Kymmell, W. (2008). Building Information Modeling : Planning and Managing Construction Projects with 4D CAD and Simulations (McGraw-Hill Construction Series) : Planning and Managing Construction Projects with 4D CAD and Simulations. McGraw-Hill Publishing.

Mashwama, X. N., Aigbavboa, C., and Thwala, D. (2016). Investigation of Construction Stakeholders' Perception on the Effects \& Cost of Construction Dispute in Swaziland. Procedia Engineering, 164, 196-205.

Niemand, T., \& Mai, R. (2018). Flexible cutoff values for fit indices in the evaluation of structural equation models.Journal of the Academyof Marketing Scinece, 46(6),11481172

Olawumi, T. O., \& Chan, D. W. M. (2019). An empirical survey of the perceived benefits of executing BIM and sustainability practices in the built environment. Construction Innovation, 321-342.

Reid, C. A., Kolakowsky-Hayner, S. A., Lewis, A. N., \& Armstrong, A. J. (2007). Modern psychometric methodology: Applications of item response theory. Rehabilitation Counselling Bulletin, 50(3), 177-188

Saka, A. B., Chan, D. W., \& Siu, F. M. (2019). Adoption of building information modelling in small and medium-sized enterprises in developing countries: a system dynamics approach. 
Volume 6 Issue 24 (December 2021) PP. 100-108 DOI: 10.35631/JISTM.624010

Wei, A. N., \& Mydin, M. A. O. (2017). Potential and benefits of Building Information Modeling (BIM) during pre-construction, construction and post construction stage. Analele Universitatii'Eftimie Murgu, 24(1), 429-438.

Williams, L. J., \& Edwards, J. R. (2003). Recent Advances in Causal Modeling Methods for Organizational and Management Research Journal of management, 29(6), 903-936.

Williamson, O. E. (1983). Markets and hierarchies : analysis and antitrust implications : a study in the economics of internal organization (Facsim. ed.). New York ;London: Free Press.

Williamson, O. E. (2014). Mechanisms of Governance : Oxford University Press.

Yates, D. J. (1998). Conflict and disputes in the development process: A transaction cost economics perspective.

Yates, D. (2002). Reducing the incidence of claims and disputes in construction contracts. In Procurement Systems \& Technology Transfer: CIB W92 Procurement Systems Symposium (Vol. 221, p. 234). 